\title{
Design emocional e centrado no humano na construção da interação remota com o público idoso asilado em tempos de COVID-19
}

\author{
Emotional and human-centered design in the construction of a \\ remote interaction with care home residents in COVID-19 times
}

Karina de Abreu Antoniolli, Juliana Bueno

design emocional, design centrado no humano, design da informação, idosas asiladas, comunicação remota

Idosos residentes em instituições de longa permanência relembram constantemente suas histórias. Assim, o trabalho de conclusão de curso "As Meninas do Lar Iracy" objetiva em suas primeiras etapas coletar dados e requisitos para a criação de um produto gráfico baseado nas memórias afetivas de idosas asiladas, pautado em uma adaptação dos processos de Design Centrado no Humano de IDEO (2015) e o de Design Centrado na Emoção de Matter-Mind Studio (2018), composta de 4 fases. Descreve-se neste artigo o processo de interação e comunicação remota para criação de vínculo com estas idosas, no intuito de coletar requisitos informacionais. Como resultado preliminar apresenta-se a proposição do processo em si e dados coletados para a futura elaboração de um projeto gráfico.

emotional design, human-centered design, information design, care home residents, remote communication

Elderly residents of long-term care institutions often recall their stories. Therefore, the final paper "The girls from Lar Iracy" in its first stages aims to collect data and requirements for the creation of a graphic product based on the affective memories of care home residents, based on an adaptation of the Human-Centered Design process by IDEO (2015) and Emotion-Centered Design process by Matter-Mind Studio (2018), with 4 phases. This article describes the process of remote interaction and communication to create a bond with these elderly women, in order to collect informational requirements. As a preliminary result, the proposal of the process itself and data collected for the future elaboration of a graphic project are presented.

\section{Introdução}

Instituições de Longa Permanência para Idosos (ILPIs) representam segurança para aqueles em situação de risco, e no contexto de uma mudança para estas, idosos relembram constantemente suas histórias, valores e hábitos (Carli et al., 2012). No contexto pandêmico atual, as ILPIs não têm permitido visitas, fazendo com que idosos asilados se sintam mais solitários durante o isolamento social, apoiando-se nas tecnologias digitais para se sentirem lembrados (Petrocilo, 2020).

Anais do $10^{\circ} \mathrm{CIDI}$ e $10^{\circ} \mathrm{CONGIC}$

Kelli C.A.S. Smythe, Rafael de Castro Andrade (orgs.)

Sociedade Brasileira de Design da Informação - SBDI

Curitiba | Brasil | 2021
Proceedings of the $10^{\text {th }} \mathrm{CIDI}$ and $10^{\text {th }}$ CONGIC

Kelli C.A.S. Smythe, Rafael de Castro Andrade (orgs.)

Sociedade Brasileira de Design da Informação - SBDI Curitiba | Brazil | 2021 
Ao se pautar em princípios de Design Emocional (Desmet, 2002; Norman, 2004; MatterMind Studio, 2018) e Centrado no Humano (Krippendorff, 2000; IDEO, 2015), neste artigo apresenta-se o processo de comunicação e interação com idosas asiladas, levando em consideração o contexto (pandêmico e de comunicação remota). Assim, o objetivo deste processo é criar um vínculo entre pesquisador e idosas participantes a fim de coletar requisitos informacionais e de projeto durante o isolamento social, por meio de entrevistas e conversas remotas.

Além disso, este artigo é um recorte do trabalho de conclusão de curso "As Meninas do Lar Iracy", que propõe desenvolver futuramente um projeto gráfico que resgate e valorize histórias e memórias afetivas de 28 idosas residentes da Casa de Repouso Lar Iracy, em Curitiba - PR.

Tem-se como pressuposto que o processo aqui detalhado pode ser usado como base em demais projetos gráficos que partam da necessidade de uma interação e comunicação remota com idosos em ILPIs.

\section{Fundamentação teórica}

\section{Design Emocional}

Desmet (2002) define que a aparência de um produto, que é percebida pelos 5 sentidos, gera e influencia sentimentos, humor e emoções de diversas formas, assim como sua utilização. Para este, emoções, relacionadas a eventos e também produtos, surgem de julgamentos involuntários. Para o autor, por emoções relevantes aos produtos partirem de 3 variáveis estímulo, preocupação e avaliação - não é o produto em si que incita uma emoção, mas um significado pessoal atribuído.

Já para Norman (2004), objetos são mais do que apenas artefatos utilitários, existindo um componente pessoal em cada um além do design. Pessoas podem se orgulhar de objetos sem valor monetário algum pelo significado pessoal, trazendo à tona emoções fortes e positivas como apego, felicidade e até amor (Norman, 2004).

Produtos podem ganhar significados simbólicos se as pessoas os associarem a experiências, memórias ou ideias, e então o designer, ao reconhecer a parte do usuário na criação de significados, elabora um produto que aceita a narrativa pessoal de quem interage (Casais et al., 2018).

\section{Design Centrado no Humano}

Como define Krippendorff (2000), as pessoas não reagem às qualidades físicas das coisas, mas sim, pelo que estas significam. O autor coloca que o Design Centrado no Humano implica uma preocupação na maneira de lidar com os objetos, colocando em pauta diferenças culturais e individuais.

Nesse contexto, um processo centrado no ser humano começa pelas pessoas para as quais se está projetando (IDEO, 2015), examinando suas necessidades e desejos, em seguida, as ideias das pessoas são traduzidas em alternativas e, por fim, implementadas. 


\section{Coleta de informações}

Dentre técnicas para coletar dados, uma entrevista semi-estruturada é realizada a partir de um roteiro com perguntas principais, que podem ser complementadas, possibilitando uma coleta de informações mais espontânea, se comparada com uma entrevista totalmente estruturada (Manzini, 1991).

Já o storytelling é a arte de contar histórias, em que a evocação de memórias afetivas acontece por meio de narrativas (Júnior \& Silva, 2019). Esse compartilhamento de narrativas também pode ser feito remotamente, como no storytelling digital, que permite o uso de diferentes mídias para a criação de uma história interessante (Robin, 2008).

Relacionado ao design, o storytelling pode auxiliar produtos a fisgar a atenção das pessoas, incentivando ações e comportamentos. Portanto, o design utiliza cores, materiais, formas, linguagem e métodos para dar significado às coisas e incorporar valores (Lupton, 2020).

\section{Metodologia}

\section{Processo de design}

Para o projeto, utiliza-se uma adaptação do processo para Design Centrado no Humano da IDEO (2015) e o para Design Centrado na Emoção de Matter-Mind Studio (2018), composta por 4 fases: Pesquisa, Criação, Implementação e Análise. Dentro disso, as etapas são divididas entre as perspectivas concreta e abstrata. Em Pesquisa, ocorrem as etapas Fundamentar e Ouvir (enfoque deste artigo), destacadas na Figura 1, com pesquisas teóricas (perspectiva abstrata) e o contato com as idosas asiladas (perspectiva concreta). O desenvolvimento deste contato com as idosas ocorreu com base em literatura relacionada à design (gráfico e da informação) e sobre trabalhos com o público idoso.

Figura 1: Processo de Design. Fonte: IDEO (2015), Matter-Mind Studio (2018), adaptado pelas autoras.

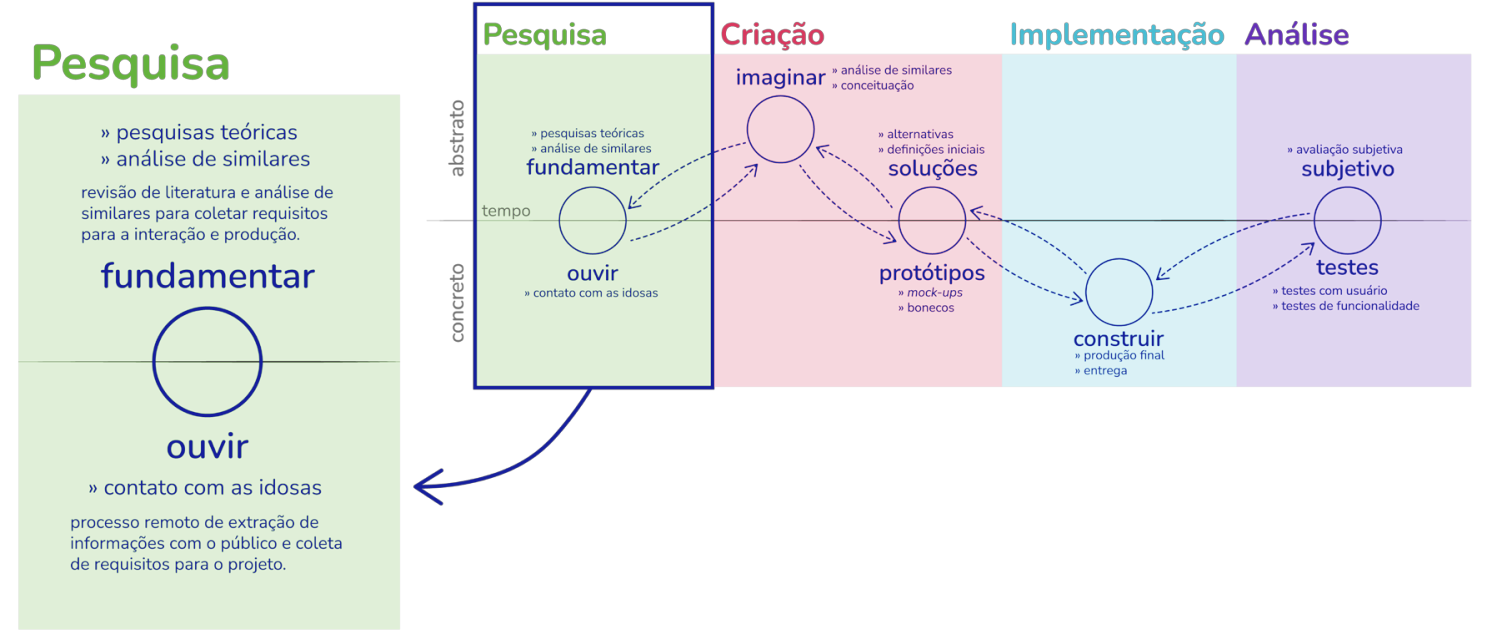




\section{Processo de comunicação e interação}

Vale considerar que a coleta de informações na etapa "Ouvir" contou com dois desafios para a pesquisa: (1) criar um vínculo entre pesquisadora e idosas asiladas, para que memórias afetivas pudessem ser relatadas; (2) administrar esta interação com recursos digitais e de forma remota.

O diálogo com as 28 residentes do Lar foi totalmente remoto, com uma distância de $582 \mathrm{~km}$ entre os lados do projeto. Assim, as informações são enviadas via recursos online ao Lar, e objetos por meio de transportadoras. Estes objetos utilizados durante as partes de aproximação, foram produzidos, em sua maioria, manualmente e especificamente para serem entregues às residentes, de maneira a estimular lembranças, com elementos conhecidos por elas, como costuras e artesanatos. No local, a administração se comunica diretamente com as idosas.

Sendo assim, houve a necessidade de, a partir da revisão de métodos e técnicas de coleta de memórias afetivas e storytelling, estipular um processo de comunicação e interação tomando como base a Regra de Três colocada por Lupton (2020), como uma história em três partes. Neste intuito, o processo foi dividido em 3 partes: Compreensão do Contexto, Criação de Empatia e Abertura para Narrativa.

Compreensão do contexto: a primeira parte da criação de vínculo proposta foi uma campanha para arrecadação de doações no final de abril de 2020, para ajudar o Lar como instituição.

Criação de Empatia: iniciada em outubro de 2020, envolveu a organização de um perfil das moradoras para o projeto em conjunto com a administração, entrevistas e entrega de presentes de Natal, criados considerando o dia a dia das residentes. Um roteiro com possibilidade de adaptações foi desenvolvido juntamente à administração para as entrevistas semi-estruturadas. Sendo o primeiro contato mais direto com as senhoras, as primeiras perguntas eram simples e relacionadas ao dia a dia destas. Em seguida, as perguntas eram relacionadas à vivência na casa de repouso. Por fim, as idosas eram questionadas sobre suas histórias e memórias. $\mathrm{O}$ registro das respostas aconteceu em vídeo. Nestes vídeos, as respostas para cada pergunta foram variadas. Como exemplo, coloca-se que uma das senhoras ao ser questionada sobre aprendizados da vida colocou: "aprendi a gostar das pessoas, aprendi a gostar de mim mesma, que eu não gostava, entende? Eu hoje em dia sou apaixonada por mim".

Abertura para narrativa: a terceira parte da criação de vínculo foi executada em fevereiro de 2021, em torno de um vídeo de contação de histórias, gravado pela autora e enviado às idosas, utilizando técnicas de storytelling digital. Esta parte foi pensada considerando o distanciamento das participantes em relação ao projeto. Também, ao apresentar a história de outra idosa para as residentes, objetivou-se que se sentissem confortáveis para também compartilhar suas histórias. Em um vídeo, a autora conta sua conexão com a costura e sua avó, que produz pantufas de inverno, com cenas de contextualizado e interação com esta. Neste, as residentes do Lar são convidadas a participar respondendo perguntas e a contarem sobre si. O registro das respostas foi feito em forma de vídeos também. 


\section{Resultados}

Levando em consideração o processo exposto, considera-se que os resultados conseguidos foram até então satisfatórios, entretanto, é necessário mais uma ou duas rodadas de interações para que os requisitos informacionais de cada idosa sejam pertinentes para aplicação no projeto, que no caso será um Álbum de Memórias.

A resposta de interação das idosas para com as técnicas empregadas demonstrou que o caráter afetivo da "Abertura para Narrativa" foi o que mais possibilitou a aproximação com as idosas, com maior compartilhamento de memórias. A figura 2 ilustra que este nível de aproximação com o público aumenta de acordo com o tempo e aplicação das técnicas de contato.

Desta interação e da revisão de literatura completa, foi possível coletar algumas direções preliminares. Estas podem ser utilizadas e adaptadas para processos similares, que tenham o contato com idosos asilados como tópico. São elas:

- Considerar a personalidade e valores de cada idosa;

- Adaptar o vocabulário durante interação para o entendimento do público-alvo;

- Coletar informações por técnicas mais informais, facilitando a abertura para compartilhamento de histórias;

Figura 2: Resultados do processo de comunicação. Fonte: autoras.






\section{Considerações finais}

Neste artigo, descreveu-se o processo de comunicação e interação em três partes com idosas residentes na Casa de Repouso Lar Iracy, com a criação de um vínculo a partir de conversas e entrevistas. Entende-se que tal processo de comunicação, com direções preliminares, pode auxiliar demais projetos que necessitem realizar uma comunicação remota com idosos asilados.

O recorte aqui descrito faz parte do trabalho de conclusão de curso "As Meninas do Lar Iracy", ao se basear no Design Emocional e Centrado no humano, objetiva desenvolver futuramente um projeto gráfico para valorizar histórias de idosas asiladas, com levantamento de informações remoto.

Com a aproximação, percebeu-se uma maior abertura ao projeto. Entretanto, identificou-se uma necessidade de novos contatos. Assim, os próximos passos são a organização e realização de novas interações, desenvolvimento de um produto gráfico, validações e entrega.

\section{Referências}

Carli, L., Kolankiewicz, A. C. B., Loro, M. M., Rosanelli, C. de L. S. P., Sonego, J. G. \& Stumm, E. M. (2012). Sentimentos e percepções de idosos residentes em uma instituição asilar. Revista de Pesquisa Cuidado é Fundamental Online, 4(2), 2868 - 2877. Recuperado de https://www.redalyc.org/articulo.oa?id=505750893004

Casais, M., Mugge, R., \& Desmet, P. M. A. (2018). Objects with symbolic meaning: 16 directions to inspire design for wellbeing. Journal of Design Research, 16(3/4), 247 - 281. Recuperado de https://www.inderscience.com/info/inarticle.php?artid=99538. doi: 10.1504/JDR.2018.099538

Desmet, P. M. A. (2002). Designing Emotions. Delft: Delft University of Technology.

IDEO. (2015). The Field Guide to Human-Centered Design. 2. Ed. Disponível em http://www.ideo.com/work/human-centered-designtoolkit/

Júnior, M. A. B., \& Silva, M. M. da. (2019). A utilização do Storytelling para o resgate da memória afetiva: Uma análise do vídeo "Os últimos desejos da Kombi". In: Vilela, M. D., \& Júnior, M. A. B. (org.). Conexões digitais e convergentes: sentidos, afeto e cultura (pp. $53-$ 70). Santa Catarina: Editora Unisul. Recuperado de https://riuni.unisul.br/handle/12345/9187

Krippendorff, K. (2000). Design Centrado no Ser Humano: uma necessidade cultural. Estudos em Design, Rio de Janeiro, 8(3), 87 - 98.

Lupton, E. (2020). O design como storytelling. São Paulo: Gustavo Gilli.

Manzini, E. J. (1991). A Entrevista na Pesquisa Social. São Paulo: Didática, v. 26 - 27.

Matter-Mind Studio. (2018). Emotion-Centered Design. What Is Emotion-Centered Design?. Disponível em https://medium.com/emotion-centereddesign/what-is-emotion-centereddesign-c3282931f9a4

Norman, D. A. (2004). Emotional Design: Why We Love (or Hate) Everyday Things. Nova York: BASIC BOOKS. 
Petrocilo, C. (2020). Proibidos de receberem visitas, idosos estão mais solitários nos asilos. Folha de São Paulo, São Paulo. Disponível em https://www1.folha.uol.com.br/cotidiano/2020/04/proibidos-de-receberem-visitas-idososestao-mais-solitarios-nosasilos.shtml

Robin, B. R. (2008). Digital Storytelling: A Powerful Technology Tool for the 21st Century Classroom. Theory Into Practice, 47(3), 220 - 228. Recuperado de https://www.tandfonline.com/doi/abs/10.1080/00405840802153916. doi: $10.1080 / 00405840802153916$

\section{Sobre as autoras}

Karina de Abreu Antoniolli, Graduanda, UFPR, Brasil <antoniolli.kari@gmail.com> Juliana Bueno, Doutora, UFPR, Brasil <julianabueno.ufpr@gmail.com> 